\title{
Towards Systems Intelligent Approach in Empathic Design
}

\author{
Satu Jumisko-Pyykkö \\ Häme University of Applied Sciences, HAMK Smart \\ Research Unit \\ satu.jumisko-pyykko@iki.fi \\ Eero Tiilikainen \\ Vincit \\ eero.tiilikainen@vincit.fi
}

\begin{abstract}
Empathy is an essential part of modern design in which application areas have become more complex, diverse, and broad. A goal of this paper is to introduce a holistic Systems Intelligence (SI) approach and apply it to empathic design. SI is characterised by the primacy of the whole, acknowledging interconnectivity, interdependence, and systemic feedback. The framework of SI tactics in empathic design with eight key factors and 32 tactics are presented, and partly utilised and validated in two case studies. The framework can help actors to apply SI in empathic design challenges.
\end{abstract}

\section{CCS CONCEPTS}

- Human-centered computing, Human-computer interaction (HCI), HCI theory, concepts and models;

\section{KEYWORDS}

System Intelligence, Empathic design, Empathy, Design process

\section{ACM Reference Format:}

Satu Jumisko-Pyykkö, Teemu Viita-Aho, Eero Tiilikainen, and Esa Saarinen. 2021. Towards Systems Intelligent Approach in Empathic Design. In Academic Mindtrek 2021 (Mindtrek '21), June 01-03, 2021, Tampere/Virtual, Finland. ACM, New York, NY, USA, 13 pages. https://doi.org/10.1145/3464327. 3464370

\section{INTRODUCTION}

Human participation is an essential part of modern design. A goal of empathic design is to understand what is meaningful to people and why, and utilise this understanding in developing acceptable products, services, systems or imagining alternative futures, and in making design decisions [1]. Over the years, the scope of design has become broader, as have the challenges to be solved. It has extended from products to services, systems and communities, and to experiences, emotions, interactions, sustainability, serving, and transformations [2] [3]. While solving more complex and wicked

Permission to make digital or hard copies of all or part of this work for personal or classroom use is granted without fee provided that copies are not made or distributed for profit or commercial advantage and that copies bear this notice and the full citation on the first page. Copyrights for components of this work owned by others than ACM must be honored. Abstracting with credit is permitted. To copy otherwise, or republish, to post on servers or to redistribute to lists, requires prior specific permission and/or a fee. Request permissions from permissions@acm.org.

Mindtrek '21, June 01-03, 2021, Tampere/Virtual, Finland

(C) 2021 Association for Computing Machinery.

ACM ISBN 978-1-4503-8514-5/21/06 . \$ \$15.00

https://doi.org/10.1145/3464327.3464370

\author{
Teemu Viita-Aho \\ Vincit
}

teemu.viita-aho@vincit.fi

\author{
Esa Saarinen \\ Aalto University, Department of Industrial Engineering \\ and Management \\ esa.saarinen@aalto.fi
}

challenges, designers need more holistic, frameworks, processes, methods, and tools to support empathy in design.

Previous research has underlined the importance of moving beyond methods to frameworks in empathic design [1] [4] [9]. The frameworks which deeply target empathy as a sensitivity to humans and collaboration are still rare. For example, Smeenk et al., [10] proposed five factors to operationalise empathy in design, and later Smeenk et al., [1] constructed an empathic formation compass to support designers' understanding and reflection in co-design. Beyond these exceptions, empathic design tends to reflect narrow and utilitarian views on empathy [4] [6]. In recent research, the systems' thinking lenses have been proposed to design for complex social service systems, service design, and change [7] [9] [11]. While these studies make the important effort of applying a systemic view in practice, they are limited in providing frameworks for empathic design for designers. In sum, there is a need to view empathy in its full potential on affective, cognitive and behavioural levels (cf. [12]), provide systemic frameworks that acknowledge subtle and deep granularities of empathy, and offer concrete practices for designers to bring these frameworks alive.

An aim of this paper is to introduce what holistic Systems Intelligence (SI) is and how to apply it to empathic design. SI is characterised by the primacy of the whole, acknowledging interconnectivity, interdependence, and systemic feedback [13]. We present a framework of SI tactics in empathic design with eight key factors named systemic perception, attunement, positive attitude, spirited discovery, reflection, wise action, positive engagement, effective responsiveness, and 32 tactics. We present two case studies to illustrate the use of the tactics and validate them. A novelty of this paper is to present a holistic SI framework which pays careful attention to empathy and offers concrete practices for empathic designers. The framework presented can help practitioners and academics to identify SI factors when empathising with users in complex design challenges.

\section{EMPATHY AND EMPATHIC DESIGN}

Empathy is a key factor of a successful social interaction. To act effectively in social connections, it is necessary to understand others, recognise their feelings and thoughts, and to affectively connect to their emotional experiences [14]. Empathy is a multidimensional construct, but there is no unified view of it. Cognitive empathy is about knowing the internal state of another person or the ability 
to intuit what another person is feeling (also referred to as cognitive empathy, perspective-taking, empathic accuracy and theory of mind) [12] [15]. This can be related to, e.g., better negotiation outcomes and satisfaction with the negotiation process, reduced stereotypes and intergroup contact (overview, [14]). Affective empathy refers to an affective connection with another person's emotional state and emotional resonance with those feelings [12] [16]. This is related to terms such as emotional contagion, affective and emotional empathy, and behavioural mimicry [15]. Behavioural empathy is a motivational component of empathy and refers to intentions to respond compassionately to the person's needs and concerns [12]. It has a strong role in effective social functioning such as helping, co-operation and improvements in intergroup relations (cf. [14]).

Past research in empathy in different disciplines has reported several benefits. In medical and nursing sciences, empathy plays a significant role in human-to-human communication, and therefore they provide valuable perspective for empathy for other disciplines. Empathy is a key factor when defining quality of care in medicine and nursing sciences [23]. Benefits of healthcare professionals' empathic engagement are psychological (e.g., decreased levels of depression, anxiety, distress, increased levels of emotional wellbeing, motivation, or satisfaction) and physiological (e.g., as improved tissue healing, immunity, cancer survival rates, blood pressure, pain) [22]. It has even been shown that patients interacting with empathic doctors recover more quickly [24]. In addition, empathy has a positive effect on staff wellness in their relationships with patients and co-workers, increase in leadership capabilities, and decrease in work conflicts (cf. [21]).

Empathy as an innate skill can be improved through training [17]. Although empathy plays a crucial role in human-to-human communication, the literature reports decreases of more than $40 \%$ in affective empathy levels during the years 1979-2009 for US college students [18]. Similarly, during medical and nursing studies, up to $50 \%$ of decline has been reported [19] [20]. To develop empathy in nurse training, both humanistic and experiential learning have been used [21]. Humanistic learning concentrates on the development of the student's self-concept with the aid of art, e.g., theatre, poems, narratives and reflection [21]. Experiential learning underlines learning through lived or shared experience and uses simulations, e.g., to stand in patient's shoes and integrate role play, scenarios, simulations, games and virtual reality [19] [21] [22]

"Empathic design aims at understanding what is meaningful to people and why, and use that understanding in making design decisions, developing products, services and systems or imagining new meaningful and alternative futures" [1].

Empathy is understood in the design context as an intuitive ability to identify with other people's thoughts and feelings such as motivations, emotions, mental models, values, priorities, preferences, and inner conflicts [25]. The nature of design practices and expected design outcomes (e.g., products, service, etc.) might direct the approach to seeing empathy as cognitive empathy. According to Mattelmäki et al., [3], empathic design focuses on sensitivities in four different layers; 1 ) Sensitivity toward humans as gathering inspiration and information about and making sense of people and their experiences and contexts; 2) Sensitivity toward collaboration as tuning the process and tools according to co-designers, decisionmakers, and organisations alike. This has an important role when design is facilitating a change; 3 ) Sensitivity toward design as seeking potential design directions and solutions; 4) Sensitivity toward techniques as an application of generative, prototyping, and visualising tools to communicate and explore the issues.

The scope and practices of empathic design have broadened during the last three decades. The roots of empathic design are in both user-centred and participatory design [2]. For example, humancentred design processes begin with empathising with users and users participating throughout the process, work being conducted in multidisciplinary teams and the nature of the design process being iterative [2] [26] [27]. The reported benefits are not only improved user experience, satisfaction, and acceptance, but also the improved quality of the system and efficiency of development, competitive advantage, and safety [28] [29]. The focus of empathic research has broadened from the design of products to services, larger systems, and communities. It has extended from products to multiple purposes such as experience, emotion, interaction, sustainability, serving, and transforming [2] [3]. Similarly, the ways of working are widened from formalised processes, methods, and tools to innovative, imaginative, co-creative, translative, participatory approaches [2] [7] [8] [26] [27] [30] [31]. For example, current design projects may include extended, even years-long projects within corporations, the public and third sectors, as well as open-ended, peer-to-peer open design initiatives [8]. Co-design in this type of project requires the interplay of strategic considerations, mundane acts of co-design work, the choice of methods and producing design outcomes [8].

There is also a need to extend current practices of empathic design. To respond to the recent scope of design, a focus on research needs to go beyond the development of methods toward frameworks to support empathy in complex and wicked design challenges [4] [5] [6] [7] [8] [9] [10]. Recently, Smeenk et al., [10] proposed five factors to operationalise empathy in design; emotional interest, sensitivity, self-awareness, personal experience and mixed perspectives. Smeenk et al., [1] have also developed an empathic formation compass to formally support designers' understanding and reflection on dimensions of emotion in co-design. Most of the current discourse on empathy is dominated by a limited view on empathy as a psychological concept. It also reflects utilitarian viewpoints to find effective ways to develop and use methods to gather and turn insights to design outcomes [1] [6].

In sum, previous research underlines the need for new empathy in design in four different ways. 1) There is a need to understand empathy in all its layers including affective, behavioural, and cognitive approaches. Previous studies on empathy in nursing, medical and work contexts have underlined dramatic positive psychological, physiological and behavioural changes. Although design is a different discipline, one may argue that the potential for higher positive empathic impacts in human-to-human communication exists there too. 2) Aligned with the requirements for broader frameworks for empathic design, there is a need to understand empathic design from a systemic perspective in a way that, at the same time, acknowledges subtle, deep and fine granularities of empathy. 3) Design as practice-driven discipline needs new ways to bring these 
frameworks into practice and designers' competencies. For example, it is necessary to facilitate and nurture reciprocal affective empathy with individual participants in studies and with a larger group of people and amongst them (e.g., workshops). These shared positive empathic moments cannot only be empowering, but also broaden the arrays of thoughts and views and build psychological resources [32]. 4) There is a need for serviceable concepts (Burke 1984 in [33]) that would help practitioners to orient themselves and also facilitate the more theoretical grasp of the structural characteristics of the empathic design process. The main aim of the current paper is to introduce holistic System Intelligence, present a framework with systems intelligence tactics in empathic design and illustrate and validate these tactics in two different case studies.

\section{SYSTEM INTELLIGENCE}

System intelligence (SI) was originally introduced by Saarinen \& Hämäläinen and defined thusly [13];

"By System Intelligence (SI) we mean intelligent behavior in the context of complex systems involving interaction and feedback. A subject acting with System Intelligence engages successfully and productively with the holistic feedback mechanisms of her environment. She perceives herself as a part of a whole, the influence of the whole upon herself as well as her own influence upon the whole. By observing her own interdependence in the feedback-intensive environment, she is able to act intelligently."

SI has multidisciplinary roots and it has been utilised in various fields. SI is inspired by several different disciplines; philosophy of everyday activity and Socratic tradition with conceptual thinking for the purpose of good life, a system approach acknowledging holism and complexity of human life, leadership for change appreciating the hidden dimensions of human subjectivity, existential situation and interaction, and humanly rich activities such as sport, music, performing arts, and successful conduct of everyday life [34]. A strong motivator for the SI approach has been the groundbreaking research on the infant-mother dyad and the relational nature of development, and their implications for adult treatment and psychotherapy [35] [36] [37]. SI has been applied in various arenas such as psychotherapy, communications, leadership and organisations, emergency management, engineering education and pedagogy, and developmental studies [38] [39] [40] [41] [42] [43] [44] [45] [46] [47] [48] [49].

SI is characterised by the primacy of the whole, acknowledging interconnectivity, interdependence, and systemic feedback [13]. The system is described by the interconnections of its elements and internal nature of those elements, has generative power beyond the modes and functionalities of elements, has emergent features not reducible to the features of its elements [13]. Everyday life takes place in systemic conditions and humans can adaptively carry out productive actions in these holistic settings. Conversation, a mother-infant dyad, party, family, village, organisation, language, and economy are examples of human systems. SI is a key form of human behavioural, life-orientational, context-adaptive and situationally creative intelligence [34]. SI is about the betterment and improvement of life, borrowed from ancient philosophy aiming at the Good Life [13].

In SI, humans can impact the entire system in numerous ways [13]. The capacity of humans is to tune in to their environment and to other subjects in several forms of instinctual, intuitive, tacit, subconscious, unconscious, inarticulate aspects, as well as awareness, mindfulness, and connectivity [13] [41]. Only some of these can be approached via the category of objective knowledge [41]. SI takes an insider's view of systems; the starting point of agents is to see the system inside and herself being part of the whole [13]. For example, a person's beliefs about co-operation with other agents can be a limiting factor in interaction and her SI [13]. The ways that a person acts with other people, approaches them and frames her/himself and the situation all impact her/his co-operative beliefs [13]. Since people are existential creatures that thrive on meaning, the most powerful forms of SI interventions may touch internally basic human aspirations [13]. They may focus on a sense of worth and a desire to be respected, a desire to feel connected to the company of others and a desire to feel connected with something meaningful [13]. Finally, human impact on the system is directed by valence, which tends to slide toward negative if a creative and conscious effector is not integrated to counterbalance this tendency [13].

The SI approach to change is optimistic and opportunistic in a way that small changes in a system can lead to positive upward spirals. SI takes an outcome-oriented approach to change and sees that intelligence-in-action is a way to create systemic change [13]. SI focuses on changes as leveraged by the dual force field of the systemic and movable nature of the human mental world and the systemic nature of the context, situation and people's behaviour around us [34]. Optimism for change can happen the way people experience small and meaningful change in other actors' behaviour, the way a person experiences action possibilities within a system caused by small and meaningful change in a system, or the way people experience the likely structure of the system in a long-term [34]. For example, in human-to-human communication, improvements in micro behaviours such as eye-contact, reciprocity or expressions of gratefulness for others, can create positive systemic growth.

SI is composed of eight factors; Systemic perception, Attunement, Positive attitude, Spirited discovery, Reflection, Wise action, Positive engagement, and Effective responsiveness (see definitions, Table 1). The factors were originally proposed [50] with the support of extensive literature review and later validated with exploratory factor analysis with a sample of 2,060 participants [48]. Expertise in these factors as systems skills are becoming key competencies for everyone who is facing and solving complex systemic challenges [52]. To create a self-report, tests for measuring an individual's or an organisation's SI, a combination of exploratory and confirmatory factor analysis was used to develop a questionnaire with 32 independent items [48] [49]. These tests correlate with emotional intelligence and organisational learning and make extensions to concrete systems and action-oriented dimensions [48] [49].

SI takes pragmatic, active, personal and existential emphasis compared to existing approaches of systems thinking [13]. In SI, the system is seen and lived from inside while system thinking clearly takes an externalist and objectifying approach to systems [34]. Optimism for change and possibilities for human flourishing 
through micro changes underlines positive aspects of SI and differentiates it from a focused examination of system failures [34]. In recent design research, soft, phenomenological, and human-centred aspects of systems thinking have been proposed in the design of complex social service systems, service design, and designing for change [7] [9] [11].

In sum, the aspects of SI that are particularly noteworthy for framing empathic design are 1) the inside-out perspective that allows the discussion of the design process beyond what the process might amount to when conceived from outside as a system, 2) the action-first aspiration of the approach, which is distinct from description-first, 3) the in-built 'optimism' in the tone of the approach in its emphasis on "being better better" [50].

\section{SYSTEM INTELLIGENCE TACTICS IN EMPATHIC DESIGN}

Eight SI factors with their definitions and 32 SI tactics in empathic design are presented in Table 1. The factors were chosen based on SI theory and its validation [48] [49] [50] [52]. The term 'tactic' refers to a planned approach, action, method, or technique for achieving a particular result. The development of tactics followed the structure of 32 SI competences [48] [49] [52] and they were transformed into an actionable form for a design context. The tactics were synthesised based on previous research on design, HCI, psychology and management. This section presents SI tactics.

\subsection{Systemic Perception}

1. Form a rich overall picture of situations by analysing stakeholders and their interactions. Stakeholder analysis is a process that defines aspects of a social and natural phenomenon affected by a decision or action; it identifies individuals, groups and organisations that are affected by or can affect those parts of the phenomenon (this may include nonhuman and non-living entities and future generations); and prioritises these individuals and groups for involvement in the design and decision-making process (modified from [51]). Its methods identify, categorise, and investigate relationships between stakeholders (cf. methods [51]). 2. Grasp what is going on by utilising practices that enable rich perspectives on human in its context to gather and analyse both tacit and explicit information (e.g., ethnography, contextual inquiry, contextual design [53]. 3. Sense essential aspects of a given situation, approaches a person as a whole and the nature of situated actions as a whole. Framing a person as a whole (vs. a user) aims at a holistic view of human, acknowledges deep human aspirations and meanings, and the ways they tune in to systems (explicit and implicit, e.g., intuitive, tacit, subconscious, unconscious and awareness, mindfulness, connectivity) and to self [13]. Situated actions shed a light on a person's activity, interaction and context [54] [56]. 4. Keeping both details and the big picture in mind indicates two-track thinking, which integrates a parallel long-term desired direction of system (e.g., a personal vision) and a solving of short-term systemic challenges and activities (e.g., probes, experimentation) [55].

\subsection{Attunement}

5. Approaching people with warmth and acceptance is at the heart of affective empathy and focuses on interactive process as nonverbal intersubjectivity and dyads. Beebe et al., [57] concluded that communicative competence is far more fundamental than language and prior to language, that, the origin of the mind is dyadic and dialogic, and that, further, adult intersubjectivity is built on infant intersubjectivity. In a dyadic system, each person's behaviour is created in a process of joint coordination in which each individual modifies and is modified by the changing behaviour of their partner (Fogel 1993 in [57]). Non-verbal and implicit communication is unconscious and emotional, and covers gaze, face, vocal, spatial orientation, touch, self-touch, posture (vs. explicit verbal, symbolic and conscious) [57]. Behavioural timing (rhythm, pausing, simultaneity, and turn-taking), independently of the content of conversation or modality, conveys important information about relatedness between partners of any age [58]. In interaction, we continuously evaluate interpersonal rhythm by tracking, comparing, and matching our partner's rhythm to our own - and based on this, we make interpretations about the valence of interaction [58]. When people experienced being in synch, they liked each other more and perceived each other more warmly [58]. These matching rhythms are connected to empathy and affect, and the promotion of co-operation, social cohesion, greater feeling of liking, similarity and trust [58] [59] [60] [61] [62]. In addition, people tend to coordinate their movements with others as demonstrated in rocking in a rocking chair, hand waving and drumming, and this coordination also happens in larger groups of people (cf.[63] [64] [65]). 6. Take into account what others think of the situation by being sensitive to situational nonverbal feedback and adapting behaviour based on it. 7. Be fair and generous with people from all walks of life by trying to be "tuned in" to others, e.g., approaching them openly, offering them attention, creating a sense of safety through eye contact and touching when appropriate [65]. One person's openness also allows others to become more open and relaxed [65]. Practicing Loving Kindness Meditation supports openness of eyes, mind and heart [65]. 8. Let other people have a voice by constructing empathising situations from a participatory mindset [2] and by making space for listening stakeholders using methods and techniques which enable their contributions to possible future design possibilities and decision-making.

\subsection{Positive Attitude}

9. Explain away mistakes by adopting an attitude of seeing failures as opportunities to learn. "Failure cultures" create motivation to take risks and try out new things even if negative effects may be the result [66]. 10. Have a positive outlook on the future by supporting ways to see the world through optimistic and flourishing lenses. Optimism as a positive mood or attitude is associated with an expectation about the social or material future, and relates to what an individual regards as desirable, advantageous, or pleasurable (Tiger 1979 in [66]). Flourishing is about optimal human functioning, a good life, fulfillment, and wellbeing [69]. Its five independent elements are positive emotion, engagement, positive relationship, meaning, and accomplishment [69]. Positive emotions (joy, gratitude, serenity, interests, hope, pride, amusement, inspiration, awe and love) widen the array of thoughts, action urges, and precepts that spontaneously come to mind, and undo lingering negative emotions [68] [70]. Engagement covers character strengths 
Table 1: SI factors and tactics in empathic design

\begin{tabular}{|c|c|}
\hline Factors of System Intelligence $[50,52]$ & System Intelligence Tactics in Empathic Design \\
\hline Systemic perception & 1. Form a rich overall picture of situations \\
\hline \multirow{3}{*}{$\begin{array}{l}\text { Seeing, identifying and recognising systems, patterns, } \\
\text { and interconnections having situational awareness }\end{array}$} & 2. Grasp what is going on \\
\hline & 3. Sense essential aspects to a given situation \\
\hline & 4. Keep both details and big picture in mind \\
\hline Attunement & 5. Approach people with warmth and acceptance \\
\hline \multirow{3}{*}{$\begin{array}{l}\text { Engaging intersubjectivity, being present, mindful, } \\
\text { situationally sensitive and open }\end{array}$} & 6. Take into account what others think of the situation \\
\hline & 7. Be fair and generous with people from all walks of life \\
\hline & 8. Let other people have a voice \\
\hline Positive Attitude & 9. Explain away mistakes \\
\hline \multirow{3}{*}{$\begin{array}{l}\text { Keeping a positive outlook, not getting stuck on } \\
\text { negative impressions and effects }\end{array}$} & 10. Have a positive outlook on the future \\
\hline & 11. Do not easily complain about things \\
\hline & 12. Do not let problems in my surroundings get me down \\
\hline Spirited Discovery & 13. Play with new ideas \\
\hline \multirow[t]{3}{*}{ Engaging with new ideas, embracing change } & 14. Look for new approaches \\
\hline & 15. Like trying out new things \\
\hline & 16. Act creatively \\
\hline Reflection & 17. View things from many different perspectives \\
\hline Reflecting upon one's thinking and actions, challenging & 18. Pay attention to the drivers of behaviour \\
\hline \multirow[t]{2}{*}{ one's own behaviour } & 19. Think about the consequences of actions \\
\hline & 20. Take the empathic design as a platform for personal growth \\
\hline Wise Action & 21. Be willing to take advice \\
\hline Exercising long-term thinking and realising its & 22. Take into account that achieving good results can take time \\
\hline implications, understanding that consequences may & 23. Be wise in your judgements \\
\hline take time to develop & 24. Keep your cool even when situations are not under control \\
\hline Positive Engagement & 25. Contribute to the shared atmosphere in group situations \\
\hline Taking systemic leverage points and means successfully & 26. Praise people for their achievements \\
\hline \multirow[t]{2}{*}{ into action with people } & 27. Alleviate tension in difficult situation \\
\hline & 28. Bring out the best in others \\
\hline Effective Responsiveness & 29. Prepare yourself for situations to make things work \\
\hline Taking systemic leverage points and means successfully & 30. Do not easily give up when facing difficult problems \\
\hline into action with environment, being able to dance with & 31. Be able to put the first things first \\
\hline system. & 32. When things don't work, take action to fix them \\
\hline
\end{tabular}

and flow experiences while positive relationships focus on other people [69]. Meaning is about serving something bigger than self, and accomplishment is often pursued for its own sake [69]. To improve flourishing and wellbeing, behaviours of flourishing people can be learnt and evidence-based interventions can be conducted such as three-good-things, use of signature strengths, walks of awe, letters of gratitude, acts of kindness, writing about the best possible self, and empathy interventions [65] [69] [71] [72] [73] [74] [. In user research, one strategy is to explore behaviours of those who really love an activity [75] [76]. 11. Do not easily complain about things by offering points of view to balance negative emotions such as naming negative emotions, accepting, and putting them into a wider perspective [77]. 12. Do not let problems in my surroundings get me down by practicing resiliency as an ability to "bounce back" from negative emotional experiences and by flexible adaptation to the changing demands of stressful experiences [78]. There are techniques such as cultivating positive emotions, meaning making, seeing challenges through character strengths and values, cultivating optimism, and perspective taking [78] [79] [80]
[81]. For a designer, participants' frustrating, painful, or conflicting situations can contain optimal design opportunities.

\subsection{Spirited Discovery}

13. Play with new ideas by utilising convergent thinking and applying techniques such as adjust, associate, add, re-arrange, segment, re-move-ment in different arenas of life [82]. The ideation cards (e.g., PLEX) and probing questions such as "if you had a magic wand, what would you change?" can support convergent thinking [83] [84].14. Look for new approaches by co-creating with participants and exchanging ideas, experiences, and expertise in facilitated co-creation events [85]. Support a systemic view of creativity, see it containing both everyday creativity (daily problem solving and adaptation to change) and eminent creativity (creativity that has a major impact on others), and underline the positive impact of positive emotions on creativity [86]. 15. Like trying out new things by utilising experimentation to quickly gain feedback to see impact and improve actions. Complex challenges need to be 
addressed through experimenting; probing, sensing, and responding (Snowden \& Boone in [55]. Experimentation can take place from an individual level to a societal level (e.g., living labs, probes) [55] [56] [87] [88]. 16. Act creatively by actively exploring ways to do things differently, and by challenging automated actions.

\subsection{Reflection}

17. View things from many different perspectives in empathic design. Reflective situations with storytelling can support explorations from many perspectives. Reflection refers to remembering or reconstructing an event in one's memory, and further analysis or explanation, interpretation, and evaluation of the significance of the event or topic [89]. Reflection is a part of professional practice [90]. Storytelling supports reflection. People build a continuous story about self to make sense and meaning out of his/her life [91]. These stories combine a selective reconstruction of the autobiographical past, present and imagined future [91]. An experience with technology is also a story [92]. Storytelling with open-ended questions contributes rich contextual information compared to interviewing [93]. 18. Pay attention to the drivers of behaviour focuses on exploration of a participant's psychological needs. Understanding needs provides a base for possibilities that experiences are positive and personally meaningful [92] [94] [95]. Autonomy, competence, relatedness, popularity, stimulation, and security are typically listed needs [92] [95]. Laddering can be used to explore a product's meaningful associations with respect to the self [96]. 19. Think about the consequences of actions in empathic design with stakeholders. As a part of the design process, anticipate impacts from different perspectives, such as society [100], sustainability [97], values and ethics [98], wellbeing [99], and dark patterns. Studies of consequences visit the past, the present and the future [100]. Practical tools are, e.g., envisioning cards for values [101], design for product care [102] and positive practice canvasses [103]. 20. Take the empathic design as a platform for personal growth, as opposed to being merely a professional exercise. Through reflection, both designers and participants have an opportunity to gain wisdom. Self-reflection can lead to personal and general wisdom, and reflection on other people's experiences leads to general wisdom [104].

\subsection{Wise Action}

21. Be willing to take advice to support continuous development. Understand the limits of your own thinking, respect other people's heterogeneous perspectives, and listen to feedback without judgement. 22. Take into account that achieving good results can take time. From empathising with users to seeing actual behaviours and impacts (intentional and unintentional) with products takes time. Investments in the fuzzy front-end of the design process requires patience but simplifies the process later [2]. 23. Be wise in your judgements by understanding the dynamic nature of systems, imagining alternative futures, learning though small experiments, and utilising contextual information [50]. E.g., examine environmental and societal impacts and scale impacts in the temporal (e.g., five years after use) or volume (from a few to a million users) domains. 24. Keep your cool even when situations are not under control by being aware of things you can and cannot control. Take control of your emotions and ways to slow down (e.g., mindfulness) as well as possibilities to share experiences and responsibility with others [80].

\subsection{Positive Engagement}

25. Contribute to the shared atmosphere in group situations prior to and during interaction. Preparations for calm presence to support empathy in a situation begins prior to an interaction. In preparations, empty the mind and senses (by detaching oneself from preconceptions), by creating a positive emotional state to broaden thinking, and be aware of things and emotions that you bring or want to leave out of interaction [65] [70]. Supportive techniques are, for example, evidence-based practices of positive psychology, meditation, use of personally empowering content (music, videos, images), and sport (cf.[71] [105]). To build shared atmosphere, the designer/facilitator has a responsibility to lead the process and foster connection through different facilitation methods and techniques to create a sense of togetherness, respect, trust, and confidentiality from the beginning [106] [107]. During interaction, listening with whole gestalt and using active constructive listening build empathy [105]. Attention is paid to other persons' observations, feelings, needs and requests [105]. In active constructive listening, listening is done with eyes and ears. The interviewee reflects back what they see or imagine is being felt in a sensitive, appropriate manner and focuses on positive aspects to enhance pride, joy, and self-regard [108]. 26. Praise people for their achievements by supporting communication of positive events. Communication of personal positive events is associated with increased daily positive affect and wellbeing [109]. 27. Alleviate tension in difficult situations by building a connection between people, hearing their needs without judgements and expressing realistic requests [105]. 28. Bring out the best in others by underlining strengths and expressing respect. 24-character strengths can be helpful in recognising positive aspects in others [110]. To bring out the best in people and organisational level activities (e.g., to change culture, transform community, create renewal and excellence) appreciative inquiry is used [111] [112]. Its processes and activities build on strengths, starting from discovery of "the best of what is" [112]. To express respect, we can highlight actions which have a positive impact on our wellbeing and fulfilment of needs, which creates satisfaction and pleasure [105].

\subsection{Effective Responsiveness}

29. Prepare yourself for situations to make things work by being proactive, getting tuned to the best possible future, acting as if your vision were a reality, and utilising the transformative power of micro behaviours (seeing that the small things can get big things to happen) [50]. Try to understand dynamics, relations, and values between people. 30. Do not easily give up when facing difficult problems by being perseverant, aware of the assumptions behind things, and exploring the ways to reframe things or the viewpoint for yourself and others [50]. 31. Be able to put the first things first by prioritising tasks based on minimum effort to create maximum output and shared values, feedback, and connections. Explore leverage points because the elements, moments, and people which change will have the most impact on the system as a whole 
[50]. 32. When things don't work, take action to fix them by taking responsibility to act, by being brave to approach difficult topics, and by focusing on fixing things (vs. people).

\section{STUDY 1: THE DREAMS OF THE ELDERLY}

A goal of this study is to apply and validate an SI framework in an empathic service design project for seniors. The study was chosen as it covers essential aspects of SI such as an inside-out view of a system, action first to achieve tangible outcome, and in-built optimism as positive emotions and reflective of the charitable nature of the project. In addition, it focuses on complex modern digital service development processes with fuzzy front end [2] [8] and collaboration with multiple parties providing opportunities for versatile use of different tactics, and empathy as sensitivities with people and collaboration [3]. The industry-driven project was chosen because of complexity, diverse collaboration and aim at an actual outcome. In this study, the primary actors of the system are the designers/researchers and the participants in the studies. This study demonstrates systemic perception, attunement, spirited discovery, reflection, effective responsiveness, and positive engagement of SI in action.

The aim of the project was to create a web-based crowdfunding service for elderly people, with a focus on evoking system intelligently positive emotions and meaningfulness. Small additional activities in seniors' daily routines, such as concerts, watching a live ice-hockey game, petting a horse, grilling sausages in the woods, all have high potential to contribute to the wellbeing of seniors. In elderly care, seniors' necessary needs are fulfilled, but a lot of things that they liked doing in the past or in the present may not be available anymore due to limitations in movement or the lack of caring resources. This project was primarily conducted by two organisations; a non-profit organisation which has been arranging small everyday "dreams" for elderly people from the year 2016 in collaboration with group stakeholders of nurses, public and private sectors and funders. A mid-sized Finnish IT and service design company conducted the user research, design, and development of the service. This study focuses on understanding the needs for a service from different stakeholders' perspectives.

\subsection{Empathising with users}

Empathising with users was composed of three phases; stakeholder analysis, narrative interviews and a co-design workshop. The stakeholder map [51] was built in collaboration with a non-profit organisation and its purpose was to construct a holistic view from the actors and their connections related to elderly dreams. The actors were a non-profit organisation and its "Dream coordinator", nursing homes and the caretakers there, home care, relatives, and donors (individuals and organisations). The results of the stakeholder analysis guided the participant selection for narrative interviews and the co-design workshop.

5.1.1 Narrative Interviews. A goal of narrative interviews was to examine positive emotions and meaning in the participant's role and context in relation to the dreams of the elderly. A total of seven interviews were conducted; two caretakers from nursing homes, two donors from a company, one from a non-profit organisation, one voluntary worker, one organiser from a community service organisation, and one elderly person participated in the interviews. The interviews were conducted in the participants' natural living or working environments. At the beginning, a written consent form was filled in. The interviews were conducted by two designer/researchers; one focused on interviewing and discussing while the other (also a professional filmmaker) focused on gentle capturing of the stories and emotions on video. The duration of the interview was about 1.5 hours. At the end, a small thank you gift was given to the participants.

Data-collection - At the beginning of the interview, a set of visual emotion cards and names of emotions were spread out on the table to allow the participants to refer to them at any moment. This was done to support participants' emotional expression. The visual emotion cards represented emotions of positive valence and were collected from a GAPED picture database [113]. The words with emotion names represented positive emotions such as joy, gratitude, serenity, interest, hope, pride, amusement, inspiration, awe, love [70] and mild negative emotions such as uncertainty, irritation, confusion. "How are you feeling today?" was used as a training question to express emotions with the aid of supporting material given to the participants. The sense of meaning was emphasised in the semi-structured interview with questions like "What makes you wake up in the morning?", What makes you excited at work? "What is important to you in your work?", "What do you love about your work?", and "What kind of impact does your work have on society?". When are you at your best? What brings you joy? How could you improve the meaning you experience even more? The participants were also explicitly encouraged to tell autobiographical stories with as much detail as possible. The researchers used active constructive responding strategy during the interviews [108]. The unearthed stories were filmed in documentary style with two cameras simultaneously with the goal of capturing the moment as authentically and as untouched as possible.

Findings - The analysis was composed of thematic analysis, affinity diagramming and creation of narrative video. Thematic analysis was used to scan the stories to identify specific user needs [93] [114]. The captured video material was selectively transcribed based on three themes called emotions, meaning, and service-related needs (total number of notes: 192). The notes were grouped based on similarity using affinity diagramming [115]. The analysis was done by one researcher and reviewed by three independent researchers. The final categories that described the needs and design opportunities were roles (the dreamer, the dream catcher and the dream enabler), customers, a dream factory, emotions, and values, each with their own subcategories. The video material was edited down to an 11-minute short documentary. The narrative video focused on presenting the design opportunities and the participants' stories related to the design context and their emotional reactions to those stories. Selected cuts of the original documentary video are available here [116].

5.1.2 Co-design Workshops. The goal of a co-design workshop was to generate ideas concerning how the service could enable the dreams of the elderly to come true from three different perspectives: the dreamer (elderly person), the dream catcher (caretaker or relative), and the dream enabler (the donor, either an individual or an organisation). A total of 13 participants with diverse backgrounds 
took part in the workshop; two were from public sector organisations, two were from funding organisations, three from associations, two from non-profit organisation behind the service, three other people interested in the dreams of the elderly. The workshop was facilitated by three designers/researchers.

Data collection - The structure of the workshop was based around empathising with dream organisers' roles for a time, with an introduction at the beginning and conclusions at the end. Three parallel groups with a facilitator were run at the same time. The introduction began with attunement of the context of design challenge with the revisits to the project's background and purpose and building connection between participants. A narrative video was shown to support positive emotional attunement, build empathy between participants with heterogeneous backgrounds, and provide seeds for reflection on different perspectives. It was followed by introductions of the participants and free discussions. In the main body of the workshop, each of the Dream organisers' role was focused at a time. It started by introducing the role and giving examples to "tune in" to the role. For example, "the dreamer" part was presented with questions like "What do you dream about?", "Where do Dreams come from?" to help with starting the discussions. The facilitator of the group helped in starting the discussion, keeping the discussion on track, and collecting views and opinions on post-its that were put on the wall near the group. After each part, the smaller groups presented their discussions to the whole workshop group. The duration of the workshop was three hours.

Findings - The workshop as process was important. The results, which were analysed using affinity diagrams [115], focused on needs in different roles. The needs of the elderly emphasised personal dreams, stories and the need to be seen. Dream catcher's needs covered ways to recognise, implement, and make dreams visible in daily life. Dream enablers' needs covered innovative ways to reach and attract donors. After the user research phase, the development of the service began. The finding and draft wireframes were used to hand over the project to UI and visual design and later to implementation. These phases are out of the scope of this paper. The nationally awarded service can be seen [117].

\subsection{Reflection}

A goal of this section is to provide a reflection on the use of the different SI factors and tactics in the study 1 . We utilised altogether 7 different SI factors and 14 different tactics. Systemic perception was widely applied in the study design and, combined with positive attitude, seemed to create a leverage point for the vision and atmosphere of the project. Systemic perception of SI was utilised by building a stakeholder map, user interviews and workshops, and emphasis on meaning. These reflect such systemic perceptions as seeing, identifying, and recognising systems, patterns, and interconnections with situational awareness (Systemic perception; tactics 1-4). Meaning (Systemic perception; tactic 4) and positive emotion (Positive attitude; tactic 10) in user research seemed to act as a leverage point for the powerful overall vision and positively energetic atmosphere of the project (Effective responsiveness; tactic 3). The participants in the user research took an active role in reflecting meaning in work and life as serving "bigger than the self", went beyond their role, and expressed positive emotions such as contentment, gratitude, or hope. Emphasis on meaning as a greater good seemed to provide a deeper vision for the project and growth within the system. It seemed to motivate the team, focus on collective goals, and change the routine work to a motivating act for the wellbeing of others. Positive emotions seemed to spread to teams' atmosphere, support broadening of their action-thought repertoires [70], and turn the team toward an active problem-solving mode while facing challenges. The careful understanding on emotions seemed to support shaping user experience goals, brand and UX design and improve efficiency of the design process.

Positive engagement of SI was orchestrated by using projective images, emotion cards and names, and a narrative video (Positive engagement; tactics 25,28 ). Although there are significant individual differences in processing, experiencing and expressing emotions [118], it seemed that the visual and verbal material presented supported the participants expression of emotions. All participants named emotions, while some also supported it with images. Narrative video of the workshop seemed to set the stage for compassion between stakeholders and co-creation.

Focus on emotions and meaning underlined systemic perception, positive engagement, and attunement of SI. Making emotions feel present seemed to welcome the participants to be open and deeply humane. They were encouraged to exhibit openness and share feelings instead of finding rational and explicit explanations for their thoughts (Systemic perception: tactic 3). Active constructive responding was used to support interaction [108] (Positive engagement: tactic 25). Open sharing of feelings seemed to build trust within and between actors, and support sharing of honest, sensitive and diverse information. With deep and meaningful questions, it seemed that a nonverbal, confident, and strong tie between people was born. This builds reciprocal trust and the offered grounds for growth for the actors in the situation. These interrelations reflect attunement of SI as engaging intersubjectivity, being present, mindful, situationally sensitive, and open, as well as the use of all four tactics (Attunement: tactics 5-8).

Gathering emotional narratives reflected the SI factors of spirited discovery, positive attitude, and reflection. The strategies to capture narratives developed over the course of the user research (Spirited discovery: tactic 14). To capture emotional and meaningful moments, the participants were encouraged to tell stories about positive memories and related emotions. This seemed to underline valuable aspects in participant' life, provide deep insight into the subject beyond the focus of service development, and heighten empathy towards participants. The storytelling supports realisation of personal meaning and usually evokes positive emotions (e.g., enjoyment, satisfaction and fulfillment) [119] [120]. Storytelling seemed to support reflection on thinking and actions, challenging of one's own behaviour (Reflection; tactic 17), and positive attitude as keeping a positive outlook (Positive attitude; tactic 10).

\section{STUDY 2: ENTREPRENEURS' REFLECTIONS AND EXPERIENCES ON A HYBRID COACHING SERVICE}

A goal of this study is to apply and validate SI framework in an evaluation study of female entrepreneurs' experiences on hybrid 
coaching service. This study was chosen as it has essential characteristics of SI such as inside-out view on system, action first as interaction to retrospectively approach a coaching journey, and optimistic tone as focus on those who enjoyed service. An evaluation study is also a typical part of design process [26] [27]. The researcher and participants are actors of the system in this study.

This study describes an application of SI to an evaluation study of female entrepreneurs' experiences on hybrid coaching service. Reflection, positive engagement, attunement, positive attitude, systemic perception, wise action and spirited discovery of SI are utilised in this study. VENLA service was composed of coaching on an online learning platform, workshops and personally. The main themes were small data, service design, marketing, sales, values and time management. All parts of service were volitional for participants. The service was organised three times during the years 2019-2020. 19 female micro-entrepreneurs in Häme region in Finland took part in the coaching service.

\subsection{Reflective Discussions}

The goals of the reflective discussions were to revisit, reflect upon participants' coaching journey, and to study their experiences on a service. The study was named as a reflective discussion prior to the recruiting participants to underline its interactional nature and to avoid associations to an interview with predefined roles (interviewer, interviewee). We focused on oral reflection as it has gained good outcomes [121]. A total of 10 female entrepreneurs (mean years as self-employed: 10,7) took a part to the study. Their lines of businesses were beauty, wellbeing, marketing, coaching and veterinary. All participants were active users of the service (5-10+ coaching activities; $<25 \%$ of online coaching activities completed). We focused on the active user groups, as we were interested in learning from those participants' experiences who really have enjoyed their journey and find it very useful. We aim at utilising these learnings in the future service development. The study was conducted in the calm spot of participants' working environments. At the beginning the written consent was filled and the roles were clarified. The reflective discussions (duration 35-60 min) were audio-recorded and at the end, a small thank gift was given for the participants.

Data-collection - Prior to the reflective discussion, the moderator tuned in the situation by exercising mindfulness for 10 minutes. To support participant's and a moderator's attunement, a set of visual emotion cards with varied valence [113] and names of positive and negative emotions were spread on the table to let the participants refer to them at any moment. "How are you feeling today?" was used as a warming up question to express emotions with the aid of the supporting material. Both a participant and a moderator answered to this training question. The actual reflective discussion had four main themes; strengths as a human and as an entrepreneur, experiences on the coaching service, applicability and utilisation of learnings, and changes in action and performance [122]. There were open questions such as "What inspires you / what do you love in your daily life? When are you at your best? What are your strengths? What kind of journey have you made during use of coaching service? What kind of emotions the journey has evoked? How have you been able strengthen yourself during the journey? What kind experiences you have about the service? What is your most important memory about the service? How do you utilise the learnings from VENLA coaching? What kind of changes the participation to the coaching brought to you on a short / long term? If you had a magic wand, what would you change in your life?". The participants were encouraged to autobiographical storytelling. The moderator used active constructive responding strategy during the study and summarised the main points of the discussion for the participant at the end [108].

Findings - The original data was transcribed and analysed following the thematic analysis [114]. A total of 297 mentions was organised to under the four main themes; 1) The excitement and strength drivers described freedom, enjoyment and success of being a self-employed, and continuous learning. 2) Experiences on service was composed of positive experiences, inspiration, moments to stop, support and easy to apply content. While the personal coaching and workshops were inspiring, supportive, and useful, online learning platform evoked negative emotions due to bad usability (e.g. broad content, independent studying, hard to use). 3) The empowering network formed a warm and collaborative work community. 4) Versatile positive changes reflected improvements in action (productivity, efficiency, quality, new ideas into practice, motivation, renewal, time management, and wellbeing). The service was evaluated as good (mean 8,1; SD 0,9) and useful (mean 8,4; SD $1,4)$ on a scale $4-10$.

\subsection{Reflection}

A goal of this section is to provide a reflection on use of the different SI factors and tactics in study 2 . This study utilised altogether 7 different SI factors and 9 different tactics. Reflection of SI was implemented as reflective discussions to create space for reflection and gathering of experiences on the service (Reflection; tactics 17, 20). The reflective discussion provided a view to personal strengths, development process, and future. They also showed that the participants were able to combine theory and practice (e.g. bring new ideas to life) and valued changes of learning process indicating a good level of depth of reflection [121]. The results of reflective discussion are also supported by informal observations made at the end of the study. When the moderator summarised the main points of the discussion for the participant, nearly all participants expressed discussion being helpful for recapping their journey from private and professional perspective and planned to use learnings in future. The discussion also gathered experiences and development needs (e.g. usability of platform, better utilisation of community) for the service (Wise action; tactic 21). Although the current empathic design is dominated by utilitarian viewpoints to methods [4] [6], our reflective discussion approach seems to take a step further by offering both an opportunity to self-reflection and feedback for the service development.

To utilise SI tactics requires a careful and holistic design of the study. The study focused on the participants who were active users and enjoyed the activity (Positive attitude; tactic 10). Framing of the study as a reflective discussion during the recruitment phase seemed to give freedom in associations related to the working methods and roles. When preparing to the study, a moderator needs time for activities to reach a state of calm presence (Attunement; tactic 7) to be able create optimal listening conditions during a study, 
and to be aware to use active constructive responding strategy. To support positive engagement at the beginning of discussion, images and words were to ease and encourage expression. Both moderator and participant used them to describe feelings of the day to build empathy and trust. These different steps seemed to be necessary for building positive engagement of SI (Positive engagement; tactic 25). The first themes of the study focused on positive emotions (Positive attitude; tactic 10). Seeing a person as a whole (vs. as an entrepreneur) utilised systemic perception in study design (Systemic perception; tactic 3). This start with an elevating and holistic approach to humanity seemed to support and provide a wide and compassionate view throughout the situation. During a study, we aimed to evoke creativity with one playful question: "If you had a magic wand, what would you change in your life?" (Spirited discovery; tactic 13). Furthermore, the question like "What kind of changes have the participation in coaching brought you in the long term?" seemed to brace for reflection (Reflection; tactic 19). In addition to designing the possible flow of the study, SI factors and tactics seem to be helpful in the design of the content of the study.

\section{DISCUSSION AND CONCLUSIONS}

The goal of this paper was to introduce a holistic SI approach, apply to, and validate it in empathic design. We presented a framework of SI tactics in empathic design with eight key factors (systemic perception, attunement, positive attitude, spirited discovery, reflection, wise action, positive engagement, effective responsiveness) and 32 tactics. Two case studies demonstrated the use of all the factors and 18 tactics in the empathic design process.

Our work extends and specifies the current view of empathic design. To support the framework-level developments in empathic design, SI underlines the primacy of the whole, acknowledges interconnectivity, interdependence, and systemic feedback [13]. Instead of a systemic view, previous research on empathic design has focused on a designer as an individual actor, her/his empathy factors, and tools to support empathic understanding [1] [10]. The framework with SI factors and tactics deepens the current view of empathy in empathic design. For example, attunement (tactic 5) and positive engagement (tactic 10) underline that empathy is built before and during interaction, is heavily impacted by nonverbal communications parallel to verbal communication, and that the process is reciprocal in nature. This means that in empathic design, we are engaged in designing ourselves, people, and the world around us in an ongoing process [9]. Instead of empathic design, previous systemic approaches on design have focused on descriptive, phenomenological, and human-centred views [7] [9] [11]. Our SI framework extends this view with empathy, an optimistic tone of exploring possibilities for human flourishing, and tangible tools for supporting designers' practices within a system.

There are several limitations in our current research. The case studies used and validated SI factors and a set of tactics. They had a narrow variation in breadth and complexity which may have limited the full-scale use of tactics. As one may argue that a total number of tactics is high, further validations will show to what extent and depth the SI factors and tactics are useful. The reflections about the use of the tactics only focused on one type of actor within the system. This needs to be extended to cover multiple actors' views to provide a more comprehensive understanding. At this stage, SI can provide a framework with a systemic vocabulary for empathic designers.

More studies are needed to understand the relationships and patterns between the SI factors and tactics. In study 1, a focus on positive emotions and meaning in user research seemed to act as a leverage point for the powerful overall vision and positively energetic atmosphere of the project and reflected the effective responsiveness (tactic 3). This seemed to indicate the reciprocal influences within the system and the interconnected factors such as positive attitude (tactic 10) and systemic perception (tactics 1, 4). These observations also went beyond mainstream practices of identifying users' needs and expectations (e.g. [26]) and highlighted the importance of the process itself in empathic design. However, our current conclusions on leverage points are limited to one case study and require further validation.

Future work needs to address SI in successive design projects as a whole. In system thinking, a successive project is a whole which cannot be divided into interdependent elements without losing its essential properties [Ackoff 1999 in [7]]. A system's performance depends more on how its parts interact than on how they act independently of each other [7]. Our case studies focused on sensitivity toward people and collaboration while it paid less attention to sensitivity toward design and techniques [3]. Emphasis on the whole may reveal salient factors behind the success. By learning the SI factors, tactics, interactions and leverage points in such projects, designers and researchers can grasp and apply the leading practices in their future projects, and potentially help our research field to develop further.

Further work also needs to address the mindset and skills essential to SI designers in the future. Our case studies demonstrated that an SI designer needs to see him/herself as being an active part of the system, influencing and being influenced by the system (cf. similarly, a psychotherapist is a part of dyadic system with a customer [58]). Broad knowledge about working with people is required. As the tactics of systemic perception and reflection underlined, the designer needs a holistic approach to human and drivers of behaviour, skills to support reflective practice and growth, and knowledge to approach consequences. When viewing the new mindsets and skills of the designer, it is essential to bring the boundaries of designers' practice into the discussion.

To conclude, this paper introduced a holistic SI framework, its eight factors and 32 tactics to empathic design. SI framework extends the current view on empathy in empathic design by taking a systemic approach to it. Two case studies demonstrated how factors of attunement, positive engagement, positive attitude, reflection, systemic perception, wise action, effective responsiveness, and spirited discovery are exploited in practice. Further work needs to be done to deepen the understanding of SI factors, tactics, and their interactional impacts in successful empathic design projects.

\section{ACKNOWLEDGMENTS}

We thank Arvokas Vanhuus ARVA Ry, Vincit, Business Finland, ESR funded projects VENLA - Web and Mobile Training and Change Driver, Jenny and Antti Wihuri Foundation, Jukka Pulkkinen, Heidi Majuri, Marjo Vaalgamaa, Minna Tarkkala, and our participants. 


\section{REFERENCES}

[1] W. Smeenk, J. Sturm, and B. Eggen. 2019. A comparison of existing frameworks leading to an empathic formation compass for co-design. International fournal of Design, 13, 3, 53-68.

[2] E. B. N. Sanders and P. J. Stappers. 2008. Co-creation and the new landscapes of design. CoDesign, 4, 1, 5-18. DOI: https://doi.org/10.1080/15710880701875068

[3] T. Mattelmäki, K. Vaajakallio and I. Koskinen. 2014. What happened to empathic design? Design Issues, 30, 1, 67-77. DOI:10.1162/desi_a_00249

[4] J. J. Lee. 2012. Against method: The portability of method in human-centered design. Helsinki, Finland: Aalto University. 22.

[5] J. J. Lee, M. Jaatinen, A. Salmi, T. Mattelmäki, R. Smeds, and M. Holopainen, M. 2018. Design choices framework for cocreation projects. International fournal of Design, 12, 2, 15-31.

[6] J. L. Hess and N.D. Fila. 2016. The manifestation of empathy within design: Findings from a service-learning course. CoDesign, 12, 1-2, 93-111. DOI: https: //doi.org/10.1080/15710882. 2015.1135243

[7] M. van der Bijl-Brouwer. 2017. Designing for Social Infrastructures in Complex Service Systems: A Human-Centered and Social Systems Perspective on Service Design. She ji The fournal of Design, Economics, and Innovation, 3, 3, 183-197.

[8] A. Botero, S. Hyysalo, C. Kohtala, and J. Whalen. 2020. Getting participatory design done: From methods and choices to translation work across constituent domains. International fournal of Design, 14, 2, 17-34.

[9] Y. Akama, and A. Prendiville. 2013. Embodying, Enacting and Entangling, a Phenomenological View to Co-Designing Services. Swedish Design Research Journal, 13, 1, 29-40.

[10] W. Smeenk, J. Sturm, J. Terken, and B Eggen. 2018. A systematic validation of the empathic handover approach guided by five factors that foster empathy in design. CoDesign, 15, 4, 308-328. DOI: https://doi.org/10.1080/15710882.2018.1484490

[11] A. Salmi, T. Mattelmäki. 2021. From within and in-between-co-designing organizational change. CoDesign, 17,1,101-118. DOI: https://doi.org/ 10.1080/15710882.2019.1581817

[12] E. Hatfield, R. L. Rapson, Y-C. Le. 2011. Emotional contagion and empathy. In J Decety \& W. Ickes (Eds.), Social neuroscience. The social neuroscience of empathy, 19-30. MIT Press. DOI: https://doi.org/10.7551/mitpress/9780262012973.003. 0003

[13] E. Saarinen and R. P. Hämäläinen.2004. Systems Intelligence: Connecting engineering thinking with human sensitivity. Systems Intelligence, Espoo, Finland: Helsinki University of Technology, 1-29.

[14] S. Olderbak, C. Sassenrath, J. Keller, and O. Wilhelm. 2014. An emotion differentiated perspective on empathy with the emotion specific empathy questionnaire. Front. Psychol. 5, 653. DOI: https://doi.org/10.3389/fpsyg.2014.00653

[15] C. D. Batson. 2009. These things called empathy. The Social Neuroscience of Empathy, ed. J Decety, W Ickes, 16-31. Cambridge, MA: MIT Press

[16] C. D. Batson, M. P. Polycarpou, E. Harmon-Jones. 1997. Empathy and attitudes: can feelings for a member of a stigmatized group improve feelings toward the group? 7 Pers Soc Psychol 72,105-118.

[17] V.N. Kiosses, V.T. Karathanos, and A Tatsioni. 2016. Empathy promoting inter ventions for health professionals: a systematic review of RCTs. F. Compassionate Health Care, 1-22. DOI: https://doi.org/10.1186/s40639-016-0024-9.

[18] S. Konrath, E. O’Brien, C. Hsing, C. 2011. Changes in dispositional empathy in American college students over time: a meta-analysis. Personal. Soc. Psychol. Rev. 15, 2, 180-198.

[19] A. Ward, A. Mandrusiak, and T. Levett-Jones, Cultural empathy in physiotherapy students: a pre-test post-test study utilising virtual simulation. Physiotherapy, 104, 4, 453-461, ISSN 0031-9406, DOI: https://doi.org/10.1016/j.physio.2018.07. 011.

[20] M. Hong, W. Lee, J. Park, T. Yoon, D. Moon, S. Lee, and G. Bahn. 2012. Changes of empathy in medical college and medical school students: 1-year follow up study. BMC Med. Educ. 12, 122.

[21] P. Bas-Sarmiento, M. Fernández-Gutiérrez, M. Baena-Baños, A. CorreroBermejo, P.S. Soler-Martins, S. de la Torre-Moyano. 2020. Empathy training in health sciences: A systematic review. Nurse Educ Pract. 44, 102739. DOI: 10.1016/j.nepr.2020.102739.

[22] T. Levett-Jones, S. Lapkin, N. Govind, J. Pich, K. Hoffman, S. Y-S. Jeong, C. A Norton, D. Noble, L. Maclellan, M. Robinson-Reilly, N. Everson. 2017. Measuring the impact of a 'point of view' disability simulation on nursing students' empathy using the Comprehensive State Empathy Scale. Nurse Education Today, 59, 75-81, DOI: https://doi.org/10.1016/j.nedt.2017.09.007.

[23] J. Rees-Lewis. 1994. Patient's views on quality care in general practice: literature review. Soc. Sci. Med. 39, 655-671.

[24] A.M. VanDulmen, and J. M. Bensing. 2002. Health promotion effects of the physician-patient encounter. Psychol. HealthMed. 7, 289-300. DOI $10.1080 / 13548500220139421$

[25] J. F, Suri. 2003. Empathic design: Informed and inspired by other people's experience. In I. Koskinen, T. Mattelmäki, \& K. Battarbee (Eds.), Empathic design User experience in product design, 51-58. Helsinki, Finland: Edita IT Press.

[26] ISO 9241-210. 2019. Ergonomics of Human-System Interaction - Part 210: Human centred design for interactive systems. International Standardization Organization
(ISO)

[27] ISO 9241-210. 2010. Ergonomics of Human-System Interaction - Part 210: Humancentred design for interactive systems. International Standardization Organization (ISO)

[28] S. Kujala. 2002. User Studies: A Practical Approach to User Involvement for Gathering User Needs and Requirements. Acta Polytechnica Scandinavica, Mathematics and Computing Series No. 116. Espoo: the Finnish Academies of Technology.

[29] https://www.mckinsey.com/business-functions/mckinsey-design/ourinsights/the-business-value-of-design, 2018, visited 17.12.2020

[30] M. Maguire. 2001. Methods to support human-centred design. Int f Hum Comput Stud. 55, 4, 587-634

[31] B. M. Hanington. 2003. Methods in the Making: A Perspective on the State of Human Research in Design. Design Issues, 19, 4, 9-18. MIT Press, Cambridge, MA.

[32] B. Fredrickson. 2004. The broaden-and-build theory of positive emotions. Philosophical Transactions of the Royal Society London B Biological Sciences 359, 13671377

[33] P. Kenttä. 2021. A Grammar of Interactional Wellbeing in Organizational Settings. Aalto University publication series doctoral dissertations, 132/2020. ISBN: 978952-64-0021-1

[34] R. P. Hämäläinen and E. Saarinen. 2007. Systems Intelligence: A Key Competence in Human Action and Organizational Life. In R. P. Hämäläinen and E. Saarinen, eds. Systems Intelligence in Leadership and Everyday Life. Systems Analysis Laboratory, Helsinki University of Technology, Espoo.

[35] D. Stern. 1998. The Interpersonal World of the Infant: A View from Psychoanalysis and Developmental Psychology. London, Great Britain: Karnac Books.

[36] B. Beebe. 2014. My journey in infant research and psychoanalysis: Microanalysis, a social micro-scope. Psychoanalytic Psychology, 31, 1, 4-25. DOI:10.1037/a0035575

[37] S. Seligman. 2017. Relationships in development: Infancy, intersubjectivity, and attachment. New York, NY: Routledge. DOI:10.1037/0012-1649.22.4.450

[38] F. Martela and E. Saarinen. 2013. The Systems Metaphor in Therapy Discourse: Introducing Systems Intelligence. Psychoanalytic Dialogues, 23, 1, 80-101.

[39] R. Jones, J. Corner and R.P. Hämäläinen. 2011. Systems Intelligence as a Lens for Managing Personal Knowledge. In Pauleen, D.J. and Gorman, G.E. (Eds.), Personal Knowledge Management-Individual, Organization and Social Perspectives, Gower Publishing Ltd, Farnham, England, 79-98.

[40] R. Jones and J. Corner. 2012. Stages and dimensions of systems intelligence. Systems Research and Behavioral Science, 29, 1, 30-45.

[41] R. P. Hämäläinen, and E. Saarinen, E. 2008. Systems intelligence-the way forward? A note on Ackoff's Why Few Organizations Adopt Systems Thinking. Systems Research and Behavioral Science, 25, 821-825.

[42] J. Luoma, R. P. Hämäläinen, and E. Saarinen. 2008, Perspectives on team dynamics: Meta learning and systems intelligence. Systems Research and Behavioral Science, 25, 6, 757-767.

[43] J. Luoma, R. P. Hämäläinen, and E. Saarinen. 2011. Acting with systems intelligence: Integrating complex responsive processes with the systems perspective. Fournal of the Operational Research Society, 62, 1, 3-11.

[44] E. Saarinen. 2008. Philosophy for managers: Reflections of a practitioner. Philosophy of Management, 7, 1-24.

[45] E. Saarinen and T. Lehti. 2014. Inducing Mindfulness Through Life-Philosophical Lecturing. In a. Ie, C.T. Ngnoumen, and E.J. Langer, (Eds.), The Wiley Blackwell Handbook of Mindfulness. John Wiley \& Sons, Chichester, UK, 1105-1131.

[46] H. Seppänen, J. Mäkelä, P. Luokkala, and K. Virrantaus, K. 2013. Developing shared situational awareness for emergency management. Safety Science, 55, $1-9$.

[47] I. Leppänen, R.P. Hämäläinen, E. Saarinen and M. Viinikainen. 2018. Intrapersonal Emotional Responses to the Inquiry and Advocacy Modes of Interaction: A Psychophysiological Study, Group Decis Negot 27, 933-948. DOI: https://doi.org/10.1007/s10726-018-9584-8

[48] J. Törmänen, R. P. Hämäläinen and E. Saarinen. 2016. Systems intelligence inventory. The Learning Organization, 23, 4, 218-231. DOI: https://doi.org/10. 1108/TLO-01-2016-0006

[49] J. Törmänen, R. P. Hämäläinen and E. Saarinen. On the Systems Intelligence of a Learning Organization: Introducing a New Measure (unpublished manuscript)

[50] R.P. Hämäläinen, R. Jones, E. Saarinen. 2014. Being Better Better - Living with Systems Intelligence. Aalto University Publications. ISSN 1799-4985.

[51] M. S. Reed, A. Graves, N. Dandy, H. Posthumus, K. Hubacek, J. Morris, C. Prell, C. H. Quinn, L. C. Stringer. 2009. Who's in and why? A typology of stakeholder analysis methods for natural resource management. fournal of Environmental Management, 90, 5, 1933-1949. ISSN 0301-4797. DOI: https://doi.org/10.1016/j. jenvman.2009.01.001.

[52] R.P. Hämäläinen, E. Saarinen and J. Törmänen. 2018. Systems Intelligence - A Core Competence for Next Generation Engineers? Proceedings of IEEE International Conference on Teaching, Assessment and Learning for Engineering (TALE), 641-644.

[53] H. Beyer and K. Holtzblatt. 1998. Contextual design: defining customer-centered systems. San Francisco, CA, Morgan Kaufmann. 
[54] P. Dourish. 2001. Where the Action Is: The Foundations of Embodied Interaction. Cambridge, MA: MIT Press.

[55] M. van der Bijl-Brouwer. 2019. Problem Framing Expertise in Public and Social Innovation. She Fi: The fournal of Design, Economics, and Innovation, 5, 1, 29-43, ISSN 2405-8726. DOI: https://doi.org/10.1016/j.sheji.2019.01.003.

[56] S. Jumisko-Pyykkö. 2011. User-centered quality of experience and its evaluation methods for mobile television. $\mathrm{PhD}$ thesis, Tampere University of Technology.

[57] B. Beebe, S. Knoblauch, J. Rustin, and D. Sorter. 2003. Introduction A Systems View. Symposium on intersubjectivity in infant research and its implications for adult treatment. Psychoanal. Dial., 13, 6,743-841.

[58] B. Beebe and F. M. Lachmann. 2002. Infant research and adult treatment: Coconstructing interactions. Analytic Press.

[59] P. Valdesolo, J. Ouyang, and D. DeSteno. 2010. The rhythm of joint action synchrony promotes cooperative ability. F. Exp. Soc. Psychol. 46, 693-695

[60] L.K. Miles, L. K. Nind, and C. N. Macrae. 2009. The rhythm of rapport: Interpersonal synchrony and social perception. fournal of Experimental Social Psychology, 45, 585-589.

[61] D. Lakens. 2010. Movement Synchrony and Perceived Entitativity f. Experimental Social Psychology, 46, 5, 701-70.

[62] S. S. Wiltermuth and C. Heath, C. Synchrony and cooperation. Psychological Science, 20, 1-5.

[63] C. N. Macrae, O. K. Duffy, L.K. Miles and J. Lawrence. 2008. A case of hand waving: Action synchrony and person perception. Cognition, 109, 152-156.

[64] S. Kirschner and M. Tomasello. 2009. Joint drumming: Social context facilitates synchronization in pre-school children. fournal of Experimental Child Psychology, 102, 299-314.

[65] B. L. Fredrickson. 2013. Love 2.0. New York: Hudson Street Press.

[66] S. Duerr, F. Holotiuk, D. Beimborn, H.-T. Wagner and T. Weitzel. 2018. What Is Digital Organizational Culture? Insights from Exploratory Case Studies. In proceedings of HICSS 2018, 5126-5135.

[67] C. Peterson. 2000. The future of optimism. American Psychologist, 55, 1, 44-55.

[68] B. L. Fredrickson. 2001. The role of positive emotions in positive psychology: The broaden-and-build theory of positive emotions. American Psychologist, 56, 218-226.

[69] M. E. P. Seligman. 2011. Flourish: A visionary new understanding of happiness and well-being. Free Press.

[70] B.L. Fredrickson. 2013. Positive emotions broaden and build. Advances on Experimental Social Psychology, 47, 1-53

[71] S. Lyubomirsky. 2008. The how of happiness. New York: Penguin Press.

[72] A. C. Parks and R. Biswas-Diener. 2013. Positive interventions: Past, present, and future. In T. B. Kashdan, J. Ciarrochi (Eds.), Mindfulness, acceptance, and positive psychology: The seven foundations of well-being. Oakland, CA US: Context Press/New Harbinger Publications, 140-165.

[73] P.K. Piff, P. Dietze, M. Feinberg, D. M. Stancato and D. Keltner 2015. Awe, the small self, and prosocial behavior. F Pers Soc Psychol. 108, 6, 883-99. DOI: $10.1037 /$ pspi0000018.

[74] S. Lyubomirsky, and K. Layous. 2013. How Do Simple Positive Activities Increase Well-Being? Current Directions in Psychological Science, 22, 1, 57-62.

[75] H. Klapperich, M. Laschke, M. Hassenzahl, M. Becker, D. Cürlis, T. Frackenpohl, H. Köhler, K. Ludwigs, and M. Tippkämper. 2019. Mind the Gap: A Social Practice Approach to Wellbeing-Driven Design. In R. Cain and A. Petermans (eds.) Design for Wellbeing. An applied approach, Routldege.

[76] H. Klapperich, M. Laschke, and M. Hassenzahl. 2018. The Positive Practice Canvas - Gathering Inspiration for Wellbeing-Driven Design. In Proceedings of the 10th Nordic Conference on Human-Computer Interaction - NordiCHI '18, 74-81.

[77] C. Sims. 2017. Second wave positive psychology coaching difficult emotions: Introducing the mnemonic of 'TEARS HOPE'. The Coaching Psychologist, 13, 2, 66-79. ISSN 1748-1104

[78] M. M. Tugade, B. L. Fredrickson. 2004. Resilient individuals use positive emotions to bounce back from negative emotional experiences. F Pers Soc Psychol. 86, 2, 320-333. DOI:10.1037/0022-3514.86.2.320

[79] https://ppc.sas.upenn.edu/resilience-programs/resilience-skill-set, visited 10.11.2020

[80] K. Reivich and A. Shatté. 2002. The resilience factor: 7 essential skills for overcoming life's inevitable obstacles. Broadway Books.

[81] R. Brown. 2018. Dare to Lead. Random.

[82] V. E. Ross. 2006. A model of inventive ideation. Thinking Skills and Creativity, 1, 2, 120-129. ISSN 1871-1871. DOI: https://doi.org/10.1016/j.tsc.2006.06.003.

[83] A. Lucero, P. Dalsgaard, K. Halskov, J. Buur. 2016. Designing with Cards. In: Markopoulos P., Martens JB., Malins J., Coninx K., Liapis A. (eds) Collaboration in Creative Design. Springer, Cham. DOI: https://doi.org/10.1007/978-3-319-2915505

[84] https://uxdesign.cc/questions-ux-designers-should-be-asking-bc9a6ba87a34, visited 22.11.2020

[85] T. Mattelmäki and F. S. Visser. 2011. Lost in CO-X. In Proceedings of IASDR 2011, the 4th World Conference on Design Research.

[86] B.A. Hennessey and T.M. Amabile. 2010 Creativity. Annual Review of Psychology, 61, 569-598.
[87] M.E. Edwards-Schachter, C. E. Matti and E. Alcántara. 2012. Fostering Quality of Life through Social Innovation: A Living Lab Methodology Study Case. Review of Policy Research 29, 6, 672-692.

[88] L. Madeyski and M. Kawalerowicz. 2017. Software Engineering Needs Agile Experimentation: A New Practice and Supporting Tool. In: Madeyski L., Smiałek M., Hnatkowska B., Huzar Z. (eds) Software Engineering: Challenges and Solutions. Advances in Intelligent Systems and Computing, 504. Springer, Cham. DOI: https://doi.org/10.1007/978-3-319-43606-7_11

[89] U. M. Staudinger. 2001. Life reflection: A social-cognitive analysis of life review. Review of General Psychology, 5, 148-160. DOI:10.1037/1089-2680.5.2.148

[90] D. A. Schön. 1983. The Reflective Practitioner: How Professionals Think in Action. New York: Basic Books.

[91] D. P. McAdams. 2011. Narrative identity. In S. J. Schwartz, K. Luyckx, \& V. L. Vignoles (Eds.), Handbook of identity theory and research, 99-115. Springer Science + Business Media.

[92] M. Hassenzahl, S. Diefenbach, and A. Göritz. 2010. Needs, affect, and interactive products - Facets of user experience. Interacting with Computers, 22, 5, 353-362. DOI:10.1016/j.intcom.2010.04.002

[93] K. A. Gausepohl, W. W. Winchester, T. L. Smith-Jackson, L. Tonya, B. M. Kleiner, and J. D. Arthur. 2016. A conceptual model for the role of storytelling in design: leveraging narrative inquiry in user-centered design (UCD), Health and Technology, 6, 2, 125-136.

[94] M. Hassenzahl, K. Eckoldt, S., Diefenbach, M. Laschke, E. Lenz, and J. Kim. 2013. Designing moments of meaning and pleasure. Experience design and happiness. International fournal of Design, 7, 3, 21-31.

[95] K. M. Sheldon, A. J. Elliot, Y. Kim, and T. Kasser. 2001. What is satisfying about satisfying events? Testing 10 candidate psychological needs. Fournal of Personality and Social Psychology, 80, 2, 325-339. DOI:10.1037//O022-3514.80.2.325

[96] T. J. Reynolds, and J. Gutman. 1988. Laddering Theory, Method, Analysis, and Interpretation. Journal of Advertising Research 28, 11-31.

[97] K.-L. Kramer. 2012. User experience in the age of sustainability: a practitioner's blueprint. Waltham, MA.

[98] B. Friedman, P. H. Kahn, A. Borning, A. Huldtgren. 2013. Value Sensitive Design and Information Systems. In: N. Doorn, D. Schuurbiers, I. van de Poel, M. Gorman (eds), Early engagement and new technologies: Opening up the laboratory. Philosophy of Engineering and Technology, 16. Springer, Dordrecht. DOI: https: //doi.org/10.1007/978-94-007-7844-3_4

[99] D. Peters, N. Ahmadpour, and R. A. Calvo. 2020. Tools for Wellbeing-Supportive Design: Features, Characteristics, and Prototypes. Multimodal Technol. Interact. 4,40 .

[100] N. Tromp and P. Hekkert. 2019. Designing for Society: Products and Services for a Better World. London: Bloomsbury.

[101] https://www.envisioningcards.com/, visited 20.11.2020.

[102] https://designforproduct.care/wpcontent/uploads/2020/07/Product_Care_Kit. pdf visited 10.12.2020

[103] H. Klapperich, M. Laschke, M. Hassenzahl. 2018. The positive practice canvas. In Proceedings of the 10th Nordic Conference on Human-Computer Interaction, Oslo, Norway, 74-8.

[104] N. M. Weststrate, M. Ferrari, M.A. Fournier, and K.C. McLean. 2018. It was the best worst day of my life: narrative content, structure, and process in wisdom-fostering life event memories. The fournals of Gerontology: Series B: Psychological Sciences and Social Sciences, 73, 8, 1359-1373. DOI: https: //doi.org/10.1093/geronb/gby005

[105] M. B. Rosenberg. 2003. Nonviolent Communication: A Language of Life. Puddle Dancer Press, California.

[106] M. Soto. 2021. Emotional skills for service designers in co-creation practices. $\mathrm{PhD}$ thesis. Acta electronica Universitatis Lapponiensis.

[107] C. Hogan. 2007. Facilitating multicultural groups: A practical guide. Kogan Page

[108] J. Passmore and L. Oades. 2014. Positive Psychology Coaching Techniques: Active Constructive Responding. The Coaching Psychologist. 10, 2, 71-73.

[109] S. L. Gable, H. T. Reis, E. A. Impett, and E. R. Asher. 2004. What do you do when things go right? The intra-personal and interpersonal benefits of sharing positive events. Fournal of Personality and Social Psychology, 87,228 -245

[110] C. Peterson and M. E. P. Seligman. 2004. Character strengths and virtues: A handbook and classification. Washington, DC: American Psychological Association

[111] R. Stratton-Berkessel. 2010. Appreciative Inquiry for collaborative solutions. San Francisco, CA: Wiley.

[112] D. van der Haar and D. Hosking. 2004. Evaluating appreciative inquiry: A relational constructionist perspective. Human Relations, 57, 8, 1017-1036.

[113] E. S. Dan-Glauser and K. R. Scherer. The Geneva affective picture database (GAPED): a new 730-picture database focusing on valence and normative significance. Behav Res Methods 43, 2, 468-77. DOI: 10.3758/s13428-011-0064-1. PMID: 21431997.

[114] V. Braun and V. Clarke, 2006. Using thematic analysis in psychology. Qualitative research inpsychology, 3, 2, 77-101.

[115] H. Beyer and K. Holzblatt. 1998. The Affinity Diagram. In Contextual Design, 154-163, Morgan Kaufmann Publishers, Inc. 
[116] https://youtu.be/8FeOUufP5aY, visited 20.4.2021.

[117] https://unelmatehdas.arvary.fi/, visited 20.4.2021.

[118] L. Barr and J. Kahn and W. Schneider. 2008. Individual Differences in Emotion Expression: Hierarchical Structure and Relations with Psychological Distress. Journal of Social and Clinical Psychology, 27, 1045-1077.

[119] R. M. Ryan and E. L. Deci. 2001. On happiness and human potentials: A review of research on hedonic and eudaimonic well-being. In S. Fiske (Ed.), Annual review of psychology, 52, 141-166.

[120] L. A. King, J. A. Hicks, J. Krull, and A. K. Del Gaiso. 2006. Positive affect and the experience of meaning in life. fournal of Personality and Social Psychology, 90
179-196

[121] A. B. Enochsson. 2018. Reflective discussions in teacher training: A comparison between online and offline discussions of course literature in a class of preservice teachers. Educ Inf Technol 23, 303-319. DOI: https://doi.org/10.1007/ s10639-017-9602-5

[122] A.D. Diamantidis, and P. D. Chatzoglou. 2014. Employee post-training behavior and performance: Evaluating the results of the training process. Int. 7. Train. Dev. 18, 149-170. 